\title{
Predictors of Health-Related Quality of Life among Thai People with Coronary Heart Disease: A Preliminary Study
}

\author{
Kanthima Meesoonthorn, M.N.S. ${ }^{1}$, Kittikorn Nilmanat, Ph.D. ${ }^{1}$, Umaporn Boonyasopun, Ph.D. ${ }^{1}$, \\ Cathy Campbell, Ph.D. ${ }^{2}$, Jeongok Logan, Ph.D. ${ }^{2}$ \\ ${ }^{1}$ Faculty of Nursing, Prince of Songkla University, Hat Yai, Songkla, 90112, Thailand. \\ ${ }^{2}$ Department of Acute \& Specialty Care, University of Virginia School of Nursing, P.O. Box 800782, Charlottesville, \\ VA 22908-0782, United States. \\ Received 24 June 2021 • Revised 11 September 2021 • Accepted 16 September 2021 • Published online 21 October 2021
}

\begin{abstract}
:
Objective: To examine the prediction of severity of illness, health promoting behaviors, cardiac self-efficacy, and acceptance of illness on health-related quality of life (HRQOL) among Thai people with coronary heart disease (CHD) in Thailand.

Material and Methods: A cross-sectional design was used. A quota sampling was used to recruit 110 people with CHD, who met the inclusion criteria, from 20 selected hospitals across Thailand. Five self-reporting questionnaires were used: a demographic data questionnaire, Thai version of MacNew HRQOL, Thai version of Health-Promoting Lifestyle ProfileII, Thai version of Cardiac Self-Efficacy Scale Questionnaire, and the Thai version of Acceptance of IIIness Scale. Data were analyzed using descriptive statistics, a point-biserial correlation or a bivariate Pearson's correlation and multiple stepwise regression analyses.
\end{abstract}

Results: One hundred and ten people were included. Most of the participants were men (64.5\%) with an average age of $62.07 \pm 9.98$ years. Most of them (76.4\%) were best categorized as class I under the Canadian Cardiovascular Society (CCS) classification system. The findings showed that 46 percent of the variance (adjusted $R^{2}=0.46$ ) for HRQOL was explained by being CCS class I $(\beta=0.22$, $p$-value $<0.010)$, cardiac self-efficacy $(\beta=0.41, p$-value $<0.010)$ and acceptance of illness $(\beta=0.35, p$-value<0.010). Health promoting behavior was a non-significant predictor of HRQOL $(\beta=0.10, p-v a l u e=0.260)$. Conclusion: The results support the severity of illness, cardiac self-efficacy, and acceptance of illness in explaining HRQOL among people with CHD. Therefore, nursing interventions that are suitable for the severity of the disease, and aimed at boosting cardiac self-efficacy and acceptance of illness should be considered to enhance HRQOL.

Keywords: coronary heart disease, health-related quality of life, predictors factors, preliminary study

Contact: Assoc. Prof. Kittikorn Nilmanat, Ph.D.

Faculty of Nursing, Prince of Songkla University, Hat Yai, Songkla 90112, Thailand.

E-mail: kittikorn.n@psu.ac.th

(ㄷ) 2021 JHSMR. Hosting by Prince of Songkla University. All rights reserved.

This is an open access article under the CC BY-NC-ND license

(http://www.jhsmr.org/index.php/jhsmr/about/editorialPolicies\#openAccessPolicy).
J Health Sci Med Res 2022;40(4):367-378 doi: $10.31584 /$ jhsmr.2021845 www.jhsmr.org 


\section{Introduction}

Coronary heart disease (CHD) is a major health concern, because it accounts for a significant part of mortality and affects the quality of life of people. Globally, CHD accounted for $16.0 \%$ of deaths in 2019 , causing about 8.8 million deaths. ${ }^{1}$ In Thailand, the $\mathrm{CHD}$ mortality rate increased by 11 cases per 100,000 population, from 2007 to $2018 .^{2}$ CHD affected approximately 1,396 per 100,000 Thai patients in $2018 .^{3}$

Health-related Quality of Life (HRQOL) is viewed as an individual's perception of the effects of health on his/her life over time. ${ }^{4}$ It is considered as a significant health outcome and has been used to assess the burden of disease, injuries, and disabilities. ${ }^{4}$ Previous studies have found that $H R Q O L$ in people with $C H D$ could predict all-cause mortality and cardiac re-hospitalization. ${ }^{5,6}$ Prior studies have shown considerable variability in the level and patterns of HRQOL around the world. One fourth of Canadian people with $\mathrm{CHD}$ had a significant reduction in HRQOL, when comparing the first week and five years after their first catheterization. ${ }^{7}$ In contrast, Iranian people with $\mathrm{CHD}$ reported significantly decreased physical health, while mental health had increased at two-year follow up after percutaneous coronary angiography or coronary artery bypass grafts. ${ }^{8}$ Overall, HRQOL in people with CHD who received medications was at a low level in Thailand. ${ }^{9}$ This variability of life quality across countries may be explained by several factors; therefore, it is necessary to determine the factors that explain the HRQOL of people with $\mathrm{CHD}$ in Thailand.

The conceptual framework of this study was guided by the Health Promotion Model ${ }^{10}$ and an explanatory model of health promotion and quality of life. ${ }^{11}$ When health promoting behaviors (HPBs) are integrated into lifestyle, it results in improving health, functional ability, and quality of life. ${ }^{10}$ An explanatory model of health promotion and quality of life revealed that quality of life is influenced by contextual, attitudinal and behavioral factors. ${ }^{11}$ Several factors, both non-modifiable and modifiable factors, have been reported to affect HRQOL in people with CHD. Non-modifiable factors; including, age, educational level, occupation, income, and duration of disease were significantly correlated with HRQOL. In contrast, gender, residency, social status, or the number of chronic diseases were not correlated with HRQOL. ${ }^{12}$

The selected variables were considered from empirical studies, which provided evidence of strong correlation with HRQOL $(\beta>0.50, r>0.70)$. Previous studies revealed that a severity of illness had a significant association with HRQOL in people with $\mathrm{CHD}$ as well as other chronic illnesses. People with stable angina revealed that when they faced usual chest pain they experienced more anxiety, fear of death, and uncertainty about the like-hood of future heart attacks. ${ }^{13}$ A study in people with $\mathrm{CHD}$ after percutaneous coronary intervention reported that severe symptom experiences had significantly decreased their HRQOL. ${ }^{14}$ Empirical studies have shown a significant positive association between HPBs and HRQOL in people with hypertension in both Chinese and Thai populations with breast cancer and those receiving chemotherapy. ${ }^{15,16}$ Perceived self-efficacy is defined as the judgment of a person's ability to achieve a particular course of action. ${ }^{10}$ Empirical studies have found that cardiac self-efficacy was a predictor of $\mathrm{HRQOL}$ in people with heart failure and $\mathrm{CHD}$ after percutaneous coronary intervention. ${ }^{17,18}$ Acceptance of illness is defined as the non-appearance of feelings of rejection or resentment, which is always the first attribute of positive living. When people have accepted their illness, they are ready to cope and do self-management, and consequently they can move on to a new positive form of living with their disease. ${ }^{19}$ Previous studies explored the correlation between acceptance of illness and HRQOL in people with $\mathrm{CHD}^{20}$ and lung cancer. ${ }^{21}$ 
In Thailand, although several studies examined the relationships between several factors and $\mathrm{HRQOL}$ in people with $\mathrm{CHD}^{22-24}$, few studies have investigated the predictors of $H R Q O L$ in people with different types of $C H D$, and those in more than one hospital. Previous studies were conducted in only one university hospital, or with one type of people with $\mathrm{CHD}$, including people who underwent coronary artery bypass graft and percutaneous coronary intervention. ${ }^{25-27}$ Therefore, the results may not be representative of the concerns of people with CHD in Thailand. The aim of this study was to examine the factors of the severity of illness, HPBs, cardiac self-efficacy, and acceptance of illness in explaining HRQOL among people with CHD in Thailand. The conceptual framework of this study is presented in Figure 1. It was hypothesized that the severity of illness, HPBs, cardiac self-efficacy, and acceptance of illness influence HRQOL in Thai people with CHD.

\section{Material and Methods}

This study used a cross-sectional design. A quota sampling technique was used. This study aimed to be conducted at the cardiac outpatient clinic of all general hospitals across Thailand as per the Royal Thai Ministry of Health's list of 'basic information of hospitals,28. Nevertheless, from a total of 24 hospitals, one general hospital was excluded because it was selected to test the reliability for all instruments in the study. From the remaining twenty-three hospitals, two hospitals were excluded, because of an absence of institutional approval for participation, and a further one was excluded because of the COVID 19 situation, social distancing rules, and nationwide lockdown measures. Therefore, a final of twenty general hospitals were included in this study. These comprised of four hospitals in the Northern Region, nine hospitals in the Central Region, six hospitals in the Northeastern Region, and one hospital in the Southern Region. This study was conducted from November 2019 to March 2020.

Patients were purposively recruited at the cardiac out-patient clinic of each selected hospital if they were diagnosed with $\mathrm{CHD}$ for more than three months, were 18 years of age or older, could understand spoken Thai language, were willing to participate in the study procedures, and were able to answer the questions. Patients with cognitive impairment were excluded. The sample size

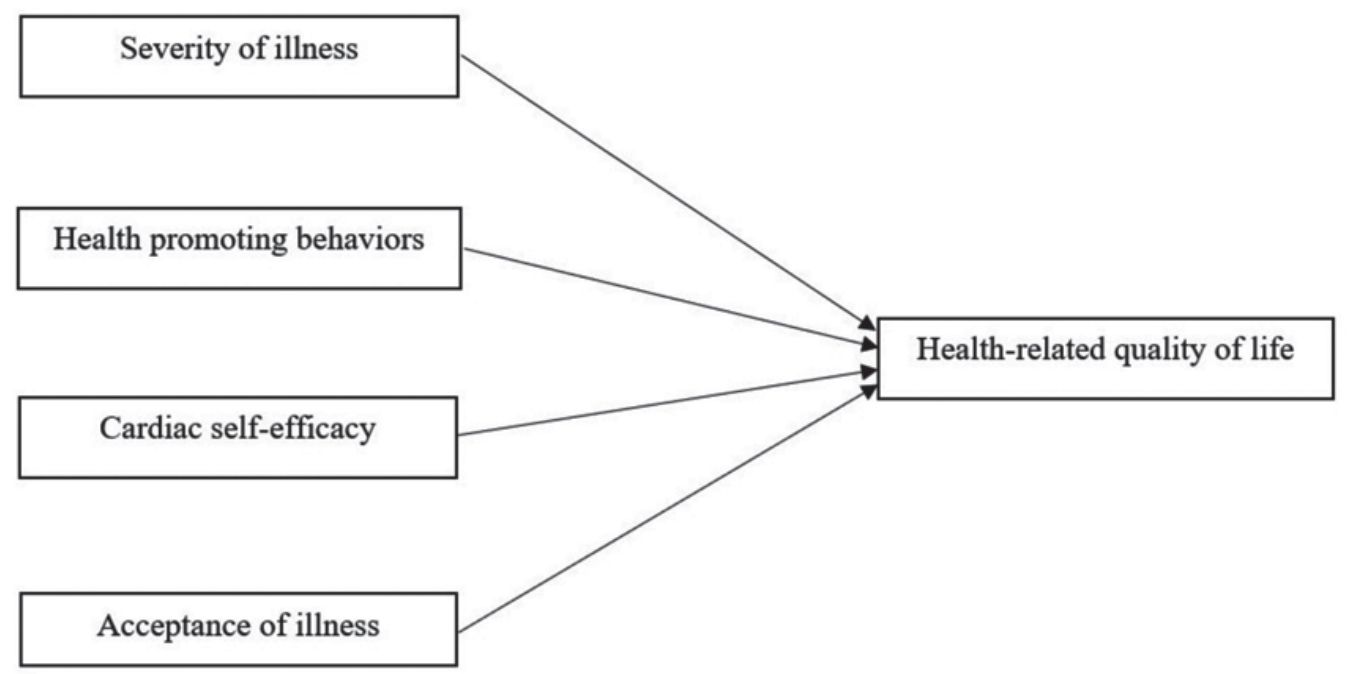

Figure 1 Conceptual frame of the study 
was estimated according to the Tabachnick and Fidell's recommendation of sample size $\geq 50+8 \mathrm{~m}$; where, $\mathrm{m}$ is the number of independent variables. ${ }^{29}$ There were four independent variables; therefore, the required sample size was $\geq 82$ cases. Furthermore, 13 participants were added after considering a 10 percent attrition rate $^{30}$, and five percent of missing data. ${ }^{29}$ The estimated total number of participants was rounded up to 110 . The number of participants was proportionate with the number of $\mathrm{CHD}$ cases who followed up at the cardio outpatient clinic in each selected hospital.

\section{Research instruments}

This study used a set of questionnaires to measure each variable and permissions were obtained from the developers. One questionnaire, the Acceptance of Illness Scale, was translated into Thai, using the back-translation approach. ${ }^{31}$ The details of the instruments used in this study are described as follows.

\section{Demographic data questionnaire}

The demographic data questionnaire used to measure socio-demographic and clinical characteristics was developed by the researchers. The socio-demographic characteristics included: age, gender, ethnicity, religion, marital status, educational level, occupation, income, and type of healthcare treatment payment. The clinical characteristics included: diagnosis, years of being diagnosed with $\mathrm{CHD}$, number of vessel occlusion and severity of occlusion, severity of $\mathrm{CHD}$, treatment, medication, underlying conditions, weight, and height. The severity of illness was assessed by using the Canadian Cardiovascular Society (CCS). The CCS determines the level of activity that causes the symptoms. Class I refers to angina on heavy exertion, but not with ordinary physical activity. Class II refers to angina that slightly limits ordinary activity. Class III refers to the limitation of ordinary physical activity. Class IV refers to angina at rest. ${ }^{32}$

\section{Thai version of MacNew HRQOL}

Thai version of MacNew HRQOL used to measure HRQOL was developed by Höfer and colleagues. ${ }^{33}$ It consists of three sub-scales, and a total of 27 items: MacNew Physical (5 items), MacNew Emotional (11 items) and MacNew Social (11 items). In each item, a sevenpoint Likert scale, ranging from 1 to 7 , is labeled. Twenty items, with seven response options ( $1=$ all the time, $7=$ not at all) were used to determine the frequency of negative emotion, limitation of social and sexual activities, chest pain or dizzy symptoms during the past two weeks. One item asked as to the level of satisfaction in life; scored from 1 (very dissatisfied) to 7 (cannot be more satisfied). One item asked about the severity of shortness of breath ( $1=$ severe shortness of breath, $7=$ no of shortness of breath). Three items asked about the level of limitation caused from CHD (1=most of limited, $7=$ not limited at all). Possible scores ranged from 27 to 189. A global HRQOL score was computed from the sum of all items, with higher values indicating a higher HRQOL level. A previous study reported a Cronbach's alpha value ranging from $0.75-$ 0.95 , test-retest correlation ranging from $0.61-0.87$, and intraclass correlation coefficients ranging from $0.73-0.95 .^{33}$ The face and content validity, construct-related validity, and criterion-related validity were recommended for international use. ${ }^{33}$ The current study demonstrated a Cronbach's alpha coefficient of 0.92 .

\section{Thai version of the Health-Promoting Lifestyle}

\section{Profile-II (HLPL-II)}

The Thai version of the HLPL-II used to measure HPBs was first developed by Walker and colleagues. ${ }^{34}$ The criterion-related validity ranged from 0.27 to 0.49 . The Cronbach's alpha coefficient value of the overall was 0.94, and its test-retest correlations was 0.89. ${ }^{34}$ Evidence has been reported for a satisfactory Cronbach's alpha coefficient among people with $\mathrm{CHD} .^{17}$ It was translated into 
the Thai version by Suwonnaroop. ${ }^{35}$ Two items had the same meaning after being translated into the Thai version, the frequency that patients inquire with health professionals about their health, and one item was deleted as a result. The Thai version consists of six domains and 51 items: health responsibilities (9 items), physical activity (7 items), nutrition (8 items), spiritual growth (9 items), interpersonal relationships ( 9 items), and stress management ( 9 items). All items ask about the frequency that each activity is practiced. A four-point Likert scale was used, and responses from 1 (never) to 4 (routinely) were rated for all items. A total HPBs score was calculated from the sum of all items, with higher values indicating a higher HPBs level: possible scores ranged from 51 to 204 . The current study revealed a Cronbach's alpha of 0.90 .

Thai version of the Cardiac Self-Efficacy Scale

\section{Questionnaire (CSEQ-T)}

The CSEQ-T used to measure cardiac self-efficacy was developed by Sullivan and colleagues. ${ }^{36}$ It was translated into Thai by Saengsiri and colleagues. ${ }^{37}$ It consists of two dimensions and 14 items-control of symptoms (SECS; 8 items) and maintenance of function (SE-MF; 6 items). In each item, a five-point Likert scale ranging from 0 to 4 is labeled. All items ask about the level of confidence $(0=$ not at all confident, $4=$ completely confident). A total cardiac self-efficacy score is calculated from the sum of all items, with higher values indicating a higher cardiac self-efficacy level. Possible scores range from 0 to 56 . Cronbach's alpha coefficients for each dimension were tested for internal consistency reliability of the two dimensions, which were 0.90 for SE-CS and 0.87 for SE-MF. It also showed good discriminant and convergent validity when associations with dissimilar and similar scales were examined. ${ }^{36}$ This instrument has indicated acceptable validity and reliability in Thai people with CHD. ${ }^{37}$ The Cronbach's alpha coefficient value was 0.82 in this present study.

\section{Thai version of the Acceptance of IIIness Scale} (AIS)

The Thai version of the AIS was used to measure acceptance of illness. It was developed by Felton and colleagues. ${ }^{38}$ It was translated into its Thai version through a back-translation procedure. ${ }^{31}$ It consists of four dimensions, and a total of 8 items: difficulties and limitations imposed by the illness ( 1 item), lack of independence; due to the illness (2 items), feeling of being dependent on others (3 items), and reduced self-esteem (2 items). In each item, a five-point Likert scale ranging from 1 to 5 is labeled. All items ask about the level of agreement with the statements about health and illness (1=strongly agree, 5=strongly disagree). A total acceptance of illness score was calculated from the sum of all items, with higher values indicating a higher acceptance of illness. Possible scores range from 8 to 40. This instrument indicated acceptable reliability and constructed validity. ${ }^{38}$ The present study features a Cronbach's alpha coefficient of 0.79 for the Thai version of the Acceptance of Illness Scale.

\section{Procedures}

This project was approved by the institutional review board (IRB)No. 2018-NSt 048, and the Health Research Ethics Board of the selected hospitals. All participants were assured of the confidentiality and anonymity of their data at all times. The purposes, process of study, the speculated benefits, potential risks, and the right to refuse or withdraw from participation were also explained to potential participants. Lastly, all participants provided written informed consent. All information that related to participants was coded, saved, reported, published, and presented by the whole data without participants' name or reference to participants.

After the IRB of each hospital granted approval, the principal investigator clearly explained to the nursing director and head nurse of each cardiac outpatient clinic what the 
purpose of the study is, the participants screening criteria, the number of participants, the data collection timeframe and gave information about the appointment of a research assistant. Before the research assistants (RAs) collected data, they completed required training on human related research and received ethical certification. RAs were further trained by the principal investigator to ensure a mutual understanding of the research project and the accuracy of the obtained data. A data collection manual, toolkits and demonstration video were used as training resources. RAs reviewed the medical records and recruited participants who met the inclusion criteria. Potential participants were given an explanation of the study protocol and the necessary permission to be interviewed was sought. All who agreed to participate completed a written informed consent form. Subsequently, the RA handed a set of questionnaires to participants. For some older participants, who had difficulties in reading, the $\mathrm{RA}$ read each item verbatim. It took approximately 40-60 minutes to complete the questionnaires.

\section{Data analysis}

Data analysis was conducted using SPSS program version 26. Data were checked and no missing data were found. All assumptions that were required for multiple regression were met. Descriptive statistics were used to describe the sociodemographic and clinical information of the study sample. A point-biserial correlation or a bivariate Pearson's correlation was used. Multiple stepwise regression analysis was performed to examine how much any $\mathrm{HRQOL}$ variance could be explained by each of the variables. The significance level of statistical testing was set at $p$-value being less than 0.050 .

\section{Results}

The sample consisted of 110 people with CHD. The majority were Buddhist (98.2\%) and married (76.4\%). Most of the participants were men (64.5\%). Mean age was $62.07 \pm 9.98$ years. The proportion of those who did not get a basic education was $5.5 \%$. The prevalence of comorbidities was $77.3 \%$. The average time of illness since diagnosis of $\mathrm{CHD}$ was $3.18 \pm 3.90$ years. Most participants $(76.4 \%)$ were categorized into Class I by CCS. More than half (55.4\%) received a combination of percutaneous coronary intervention and medication (Table 1).

The mean scores of studied variables are presented in Table 2. CCS class I, HPBs, cardiac self-efficacy, and acceptance of illness were positively associated with HRQOL ( $r=0.26, r=0.42, r=0.55, r=0.52, p-$ value $<0.010$, respectively) (Table 3 ).

Table 1 Socio-demographic and clinical characteristics $(n=110)$

\begin{tabular}{|c|c|c|}
\hline Characteristics & Number & $\%$ \\
\hline \multicolumn{3}{|c|}{ Age (years); mean $62.07 \pm 9.98, \min =40, \max =85$} \\
\hline $31-45$ & 8 & 7.3 \\
\hline $46-60$ & 36 & 32.7 \\
\hline $61-75$ & 55 & 50.0 \\
\hline $76-90$ & 11 & 10.0 \\
\hline \multicolumn{3}{|l|}{ Gender } \\
\hline Male & 71 & 64.5 \\
\hline Female & 39 & 35.5 \\
\hline \multicolumn{3}{|l|}{ Religion } \\
\hline Buddhism & 108 & 98.2 \\
\hline Islam & 2 & 1.8 \\
\hline
\end{tabular}


Table 1 (Continued)

\begin{tabular}{|c|c|c|}
\hline Characteristics & Number & $\%$ \\
\hline \multicolumn{3}{|l|}{ Marital status } \\
\hline Married & 84 & 76.4 \\
\hline Single & 5 & 4.5 \\
\hline Widowed & 17 & 15.5 \\
\hline Separated & 2 & 1.8 \\
\hline Divorced & 2 & 1.8 \\
\hline \multicolumn{3}{|l|}{ Educational level } \\
\hline No formal education & 6 & 5.5 \\
\hline Primary school & 67 & 60.9 \\
\hline Secondary school & 22 & 20.0 \\
\hline Vocational school/certificate/high school diploma & 4 & 3.6 \\
\hline Bachelor's degree & 10 & 9.1 \\
\hline Higher than Bachelor's & 1 & 0.9 \\
\hline \multicolumn{3}{|l|}{ Employment status } \\
\hline Unemployed & 28 & 25.4 \\
\hline Merchant & 11 & 10.0 \\
\hline Wage worker & 20 & 18.2 \\
\hline Farmer & 33 & 30.0 \\
\hline Self-employed & 1 & 0.9 \\
\hline Government employee & 9 & 8.2 \\
\hline Other occupation & 8 & 7.3 \\
\hline \multicolumn{3}{|l|}{ Income (baht) } \\
\hline$<5,000$ & 38 & 34.5 \\
\hline $5,000-10,000$ & 32 & 29.1 \\
\hline $10,001-20,000$ & 19 & 17.3 \\
\hline $20,001-30,000$ & 7 & 6.4 \\
\hline$>30,000$ baht & 14 & 12.7 \\
\hline \multicolumn{3}{|l|}{ Type of healthcare treatment payment } \\
\hline Universal health coverage (Thirty Baht Scheme) & 74 & 67.3 \\
\hline Social security & 9 & 8.2 \\
\hline Government/state enterprise employee & 27 & 24.5 \\
\hline \multicolumn{3}{|c|}{ Year of being diagnosed with $\mathrm{CHD}$; mean $3.18 \pm 3.90$, min=3 months, $\max =23$ months } \\
\hline$\leq 1$ & 47 & 42.7 \\
\hline $1-5$ & 45 & 40.9 \\
\hline$\geq 5$ & 18 & 16.4 \\
\hline \multicolumn{3}{|l|}{ Canadian Cardiovascular Society (CCS) } \\
\hline CCS class 1 & 84 & 76.4 \\
\hline CCS class 2 & 25 & 22.7 \\
\hline CCS class 3 & 1 & 0.9 \\
\hline \multicolumn{3}{|l|}{ Treatment } \\
\hline Medication & 31 & 28.2 \\
\hline Percutaneous coronary intervention and medication & 61 & 55.4 \\
\hline Coronary artery bypass graft and medication & 18 & 16.4 \\
\hline \multicolumn{3}{|l|}{ Underlying disease } \\
\hline Yes & 85 & 77.3 \\
\hline No & 25 & 22.7 \\
\hline \multicolumn{3}{|l|}{ BMI $\left(\mathrm{kg} / \mathrm{m}^{2}\right) ;$ mean $25.01 \pm 3.85, \min =18, \max =35$} \\
\hline Underweight & 5 & 4.5 \\
\hline Normal & 51 & 46.4 \\
\hline Overweight & 54 & 49.1 \\
\hline
\end{tabular}

$\mathrm{CHD}=$ coronary heart disease, $\mathrm{BMI}=$ body mass index 
Table 2 Descriptive statistics of study variables $(n=110)$

\begin{tabular}{llcc}
\hline Variables & Possible scores & Actual scores & Mean \\
\hline Health-related quality of life & $27-189$ & $85-185$ & 142.57 \\
Severity of illness & $1-4$ & $1-3$ & 20.51 \\
Health promoting behaviors & $51-204$ & $86-194$ & 1.25 \\
Cardiac self-efficacy & $0-56$ & $11-56$ & 36.34 \\
Acceptance of illness & $8-40$ & 19.95 & 9.52 \\
\hline
\end{tabular}

S.D.=standard deviation

Table 3 Correlation between predictors and HRQOL $(n=110)$

\begin{tabular}{|c|c|c|c|c|c|}
\hline Variable & 1 & 2 & 3 & 4 & 5 \\
\hline 1. Health-related quality of life & 1.00 & & & & \\
\hline 2. Severity of illness (Class I/other) & $0.26^{\star *}$ & 1.00 & & & \\
\hline 3. Health promoting behaviors & $0.42^{* \star}$ & 0.12 & 1.00 & & \\
\hline 4. Cardiac self-efficacy & $0.55^{* *}$ & 0.04 & $0.58^{* *}$ & 1.00 & \\
\hline 5. Acceptance of illness & $0.52^{* *}$ & 0.09 & $0.24^{*}$ & $0.35^{\star *}$ & 1.00 \\
\hline
\end{tabular}

${ }^{*} p-$ value $<0.050,{ }^{* *} p-$ value $<0.010$, CCS=Canadian Cardiovascular Society

Table 4 Predicting factors of HRQOL among people with coronary heart disease $(n=110)$

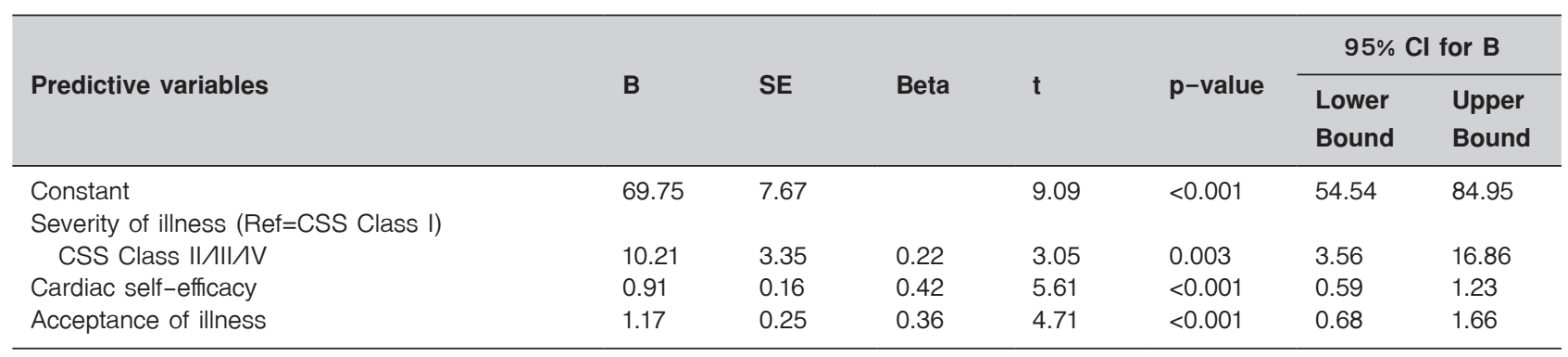

Adjusted $R^{2}=0.46, F_{3,106}=31.91, p$-value $<0.001, B=$ unstandardized regression coefficient $\mathrm{SE}=$ standard error, $\mathrm{t}=\mathrm{t}$-test, $\mathrm{Cl}=$ confidence interval, $\mathrm{CCS}=$ Canadian Cardiovascular Society

The results of the multiple stepwise regression analysis findings were that HRQOL can be significantly predicted by CCS class I $(\beta=0.22, p$-value $<0.010)$, cardiac self-efficacy $(\beta=0.41, p$-value $<0.001)$ and the acceptance of illness $(\beta=0.35, p$-value $<0.001)$. However, HPBs was a non-significant predictor of HRQOL $(\beta=0.10$, $\mathrm{p}$-value $=0.260$ ). Furthermore, CCS class I, cardiac self- efficacy, and acceptance of illness explained $46.0 \%$ of the variance of $H R Q O L$ in people with $C H D$ (adjusted $R^{2}=0.46$, $\mathrm{F}_{3,106}=31.91, \mathrm{p}$-value<0.001) (Table 4). Participants with CCS class I had a 10.21 times higher HRQOL score than CCS class 2 and 3 when adjusting for cardiac self-efficacy and acceptance of illness $(B=10.21,95 \%$ confidence interval $(\mathrm{Cl})$ 3.56-16.86, p-value=0.003). The HRQOL increased 0.91 
times for each unit score increase of cardiac self-efficacy, when adjusting for severity of illness and acceptance of illness $(B=0.91,95 \% \mathrm{Cl} 0.59-1.23, p$-value $<0.001)$. The HRQOL increased 1.17 times for each unit score increase of acceptance of illness, when adjusting for severity of illness and cardiac self-efficacy $(\mathrm{B}=1.17,95 \% \mathrm{Cl} 0.68-1.66$, p-value<0.001) (Table 4).

\section{Discussion}

In the present study, multiple stepwise regression analysis showed that severity of illness, cardiac self-efficacy and acceptance of illness are significant and independent contributing factors for HRQOL among people with CHD. Our findings revealed that cardiac self-efficacy was the best predictor of HRQOL among Thai people with $\mathrm{CHD}$. An overall multiple regression model could explain $46.0 \%$ of the variance of HRQOL.

Findings from this study revealed that cardiac selfefficacy played a key role in explaining HRQOL in people with $\mathrm{CHD}$. These findings are in line with the previous studies reporting that cardiac self-efficacy was a significant predictor of HRQOL. ${ }^{17,18}$ According to our findings, higher cardiac self-efficacy levels were accompanied by higher HRQOL in all domains; including, physical, emotional, and social domains. One explanation for our findings might be that people who reported high self-efficacy were confident that they could control their symptoms, maintain their function, and consequently lead to improving their HRQOL. Another explanation might be that many of these people did not have severe levels of CHD; most $(76.4 \%)$ participants were classified into CCS 1. It showed that they could do daily self-care activities without chest discomfort; they might not need effort to control their symptoms and maintain their function. When people with $\mathrm{CHD}$ believe that they can engage in doing something to promote health, this belief motivates them to do it successfully. The achievement brings about the sense of control over the situation, and consequently enhances life quality.
The second explaining factor associated with $\mathrm{HRQOL}$ was acceptance of illness. The influence of the illness acceptance on the level of HRQOL described in our study was also reported by Kocjan et al. ${ }^{20}$ They note an important role of acceptance of illness on HRQOL. The higher level of a patient's acceptance of illness is accompanied by better HRQOL. It is indicated that higher acceptance of illness leads to better emotional functioning, which corresponds with the study findings from Janowski et al. ${ }^{39}$ The result of our study revealed that higher acceptance of illness levels was significantly associated with higher scores in the physical, emotional, and social domains of HRQOL. A possible explanation might be that people with CHD who had high acceptance of illness could live with their illness with low effects of difficulties and limitations, such as: lack of independence, dependence on others and reduced self-esteem due to illness.

Our study found that the severity of illness was a significant predictor of HRQOL $(\beta=0.22$, $p$-value $<0.010)$ and that people with CHD, who were CCS class I, had high HRQOL. These results are similar to a study by Kim et al which found that $\mathrm{HRQOL}$ is decreased in regards to people who reported experiencing severe symptoms. ${ }^{14}$ The possible reason for these results might be that angina symptoms are common for people with CHD. People with stable angina revealed that being faced with common chest pain did not only make them more anxious and fearful of death, but also contained the uncertainty of future heart attacks. In addition, there are some limitations to the activities affecting their lifestyles. ${ }^{12}$

Surprisingly, the final model showed that HPBs did not significantly elucidate on HRQOL. In our study, a bivariate correlation between HPBs and HRQOL was found to be significant. However, HPBs were a non-significant predictor of HRQOL in multiple regressions. This finding is in contrast to previous studies, reporting the impact of HPBs on HRQOL, in regards to Chinese people with hypertension ${ }^{15}$ and Thai people with breast cancer who are receiving 
chemotherapy. ${ }^{16}$ This result can be explained by a potent influence of the severity of illness, cardiac self-efficacy and acceptance of illness on HRQOL. A possible explanation may be that most participants were found to have CHD with low severity of disease, and only a few HPBs were needed. An additional explanation for the insignificant finding could be that there was insufficient confounder adjustment in the regression model.

We acknowledge that our study had limitations. We employed a cross-sectional research design and all participants were asked to self-report their individual perceptions at a single point in time; but this may not reflect their perceptions and their changes over time. Furthermore, self-reported measures can be subject to bias and there is a large number of items that participants must complete, and this could cause more fatigue, potentially impairing the accuracy of the answers. In addition, only general hospitals with a cardiac outpatient clinic and on-site cardiologists participated in this study; potentially making our study's findings less applicable to the general population. In this study, the participants were mostly healthy, CCS levels 1 , so there are ceiling effects regarding the self-efficacy and acceptance of illness categories. Therefore, the relevance of the research findings may be limited only to people with low levels of $\mathrm{CHD}$.

\section{Conclusion}

The results of this study confirm the powerful effect of clinical and psychological factors in the enhancement of HRQOL among Thai people with CHD. It was found that illness severity, cardiac self-efficacy and illness acceptance play important roles in improving patient HRQOL. Therefore, nurses need to assess these areas and develop nursing interventions to increase HRQOL. Future research is recommended in regards to confounder adjusting in regression modeling.

\section{Acknowledgement}

The authors would like to thank Dr. Marieke K. Jones, Research Data Specialist at Claude Moore Health Sciences Library, University of Virginia, for her assistance with the statistical analyses for this project.

\section{Funding sources}

This study was funded by the Prince of Songkla University's Research Grant for Thesis Graduate School (Fiscal Year 2017), the Faculty of Nursing and Prince of Songkla University.

\section{Conflict of interest}

We declare no conflicts of interest.

\section{References}

1. World Health Organization. WHO methods and data sources for country-level causes of death 2000-2019 [monograph on the Internet]. Geneva: WHO; 2020 [cited 2021 Jan 20] Available from: https://cdn.who.int/media/docs/default-source/ghodocuments/global-health-estimates/ghe2019_cod_ methods.pdf?sfvrsn=37bcfacc_5

2. Division of Noncommunicable disease. Mortality rate separated by health service area Year Calendar 2015 [monograph on the Internet]. Nonthaburi: Ministry of Public Health; 2016 [cited 2020 Jan 18]. Available from: http://www.thaincd.com/2016/ mission/documents. php?tid=32\&gid=1-020\&searchText=\&pn=2 (In Thai)

3. Division of Epidemiology. Situation of coronary artery disease in year 2018 [monograph on the Internet]. Nonthaburi: Ministry of Public Health; 2018 [cited 2020 Jan 20]. Available from: https:// ddc.moph.go.th/uploads/files/1081120191227091554.pdf (In Thai).

4. Centers for Disease Control and Prevention. Measuring Healthy Days [monograph on the Internet]. Atlanta, Georgia: CDC, November; 2000 [cited 2020 Aug 11]. Available from: https:// www.cdc.gov/hrqol/pdfs/mhd.pdf

5. Hansen TB, Thygesen LC, Zwisler AD, Helmark L, Hoogwegt $M$, Versteeg $H$, et al. Self-reported health-related quality of life 
predicts 5-year mortality and hospital readmissions in patients with ischemic heart disease. Eur J Prev Cardiol 2015; 22:882-9.

6. Baldi C, De Vecchis R, Ariano C. The MacNew Questionnaire is a helpful tool for predicting unplanned hospital readmissions after coronary revascularization. J Clin Med Res 2016;8:210-4

7. Sajobi TT, Wang M, Awosoga O, Santana M, Southern D, Liang Z, et al. Trajectories of health-related quality of life in coronary artery disease. Circ Cardiovasc Qual Outcomes 2018; 11. doi: 10.1161/CIRCOUTCOMES.117.003661.

8. Tofighi S, Ahmad Kiadaliri A, Sadeghifar J, Raadabadi M Mamikhani J. Health-related quality of life among patients with coronary artery disease: a post-treatment follow-up study in Iran. Cardiol Res Pract 2012. doi: 10.1155/2012/973974.

9. Rerkluenrit J. Effect of learning-activated-telephone-home visiting (lath) program on quality of life among patients with coronary artery disease. Thai J Cardio Thorac Nurs [seria on the Internet]. 2019 May [cited 2021 Feb 5];30:89-101. Available from: https://he02.tci-thaijo.org/index.php/ journalthaicvtnurse/article/download/200449/140840 (In Thai).

10. Pender NJ, Murdaugh CL, Parsons MA. Health promotion in nursing practice. $7^{\text {th }}$ ed. Boston: Pearson; 2015.

11. Stuifbergen AK, Seraphine A, Roberts G. An explanatory model of health promotion and quality of life in chronic disabling conditions. Nurs Res 2000;49:122-9.

12. Barham A, Ibraheem R, Zyoud SH. Cardiac self-efficacy and quality of life in patients with coronary heart disease: a crosssectional study from Palestine. BMC Cardiovasc Disord 2019;19:290.

13. Spoletini I, Ferrari R, Rosano GMC. Living with stable angina: patients' pathway and needs in angina. $\mathrm{J}$ Cardiovasc Med (Hagerstown) 2020;21:377-82.

14. Kim HS, Kim HK, Kang KO, Kim YS. Determinants of healthrelated quality of life among outpatients with acute coronary artery disease after percutaneous coronary intervention. Jpn J Nurs Sci 2019;16:3-16.

15. Li J, Yu J, Chen X, Quan X, Zhou L. Correlations between health-promoting lifestyle and health-related quality of life among elderly people with hypertension in Hengyang, Hunan, China. Medicine 2018;97.doi: org/10.1097/MD. 0000000000010937

16. Prasertsri T, Tareepian N. Promoting behaviors and quality of life in patients with breast cancer receiving chemotherapy. J Nurs Healthc Res [serial on the Internet]. 2015 [cited 2021 Jeb 5];33:92-101. Available from: https://he01.tci-thaijo. org/index.php/jnat-ned/article/view/39493 (In Thai).

17. Loo DW, Jiang $Y$, Koh KW, Lim FP, Wang W. Self-efficacy and depression predicting the health-related quality of life of outpatients with chronic heart failure in Singapore. Appl Nurs Res 2016;32:148-55.

18. Saengsiri A, Thanasilp S, Preechawong S. Factors predicting quality of life for coronary artery disease patients after percutaneous coronary intervention. Asian Biomed (Res Rev News) 2014;8:31-42 (In Thai).

19. Ambrosio L, Senosiain García JM, Riverol Fernández M, Anaut Bravo S, Díaz De Cerio Ayesa S, Ursúa Sesma ME, et al. Living with chronic illness in adults: a concept analysis. J Clin Nurs 2015;24:2357-67.

20. Kocjan J. Is quality of life related to illness and acceptance of illness? J Educ Health Sport 2015;5:34-42.

21. Chabowski M, Polański J, Jankowska-Polanska B, Lomper K, Janczak D, Rosinczuk J. The acceptance of illness, the intensity of pain and the quality of life in patients with lung cancer. JTD 2017;9:2952-8

22. Choocherd S, Wanitkun N, Danaidusadeekul S, Yottasurodom C. Relationships among health literacy, severity of disease, patient engagement, perception of person-centered care and quality of life in patients after coronary artery bypass graft surgery. J Nurs Sci [serial on the Internet]. 2016 [cited 2021 Feb 6];34(Suppl 1):94-106. Available from: https:// he02.tci-thaijo.org/index.php/ns/article/view/77326/62032 (In Thai).

23. Junsiri K, Putwattana P, Kuwawattanasumrit K. The relationship between basic conditioning factors, self-care behaviors, and quality of life among patients after coronary stent implantation. VNJ [serial on the Internet]. 2016 [cited $2021 \mathrm{Feb} 6$ ];18:12-23. Available from: https://he02.tci-thaijo.org/index.php/vnj/ article/view/139770 (In Thai).

24. Khemthong A, Sangchan H, Nakaet K. Relationship between cardiac rehabilitation behaviors and quality of life among patients post coronary artery bypass graft. Songklanagarind $J$ Nurs [serial on the Internet]. 2018 [cited 2021 Feb 6];38:1-11. Available from: https://kb.psu.ac.th/psukb/handle/2016/ 11627 (In Thai). 
25. Buttapim S, Wanitkun N, Sindhu S, Kasemsarn C. Predictive factors of patients' quality of life three months after post coronary artery bypass graft surgery. Thai $\mathrm{J}$ Cardio Thorac Nurs [serial on the Internet]. 2018 [cited 2021 Feb 6];29:127140. Available from: https://he02.tci-thaijo.org/index.php/ journalthaicvtnurse/article/download/164289/119085 (In Thai).

26. Seangsiri A, Wattradul D, Kangchanakul S, Natthumrongkul S, Nopplub S, Wonganunnont S. The factors influencing the self-care agency and quality of life of patients with coronary artery disease. Thai J Cardio Thorac Nurs [serial on the Internet]. 2015 [cited 2021 Feb 13];26:104-118. Available from: https:// he02.tci-thaijo.org/index.php/journalthaicvtnurse/article/ view/42609 (In Thai).

27. Wannapo P, Kunsongkeit W, Duangpaeng S. Factors influencing physical activity among patients with acute myocardial infarction receiving percutaneous coronary intervention. J Health Sci Res [serial on the Internet]. 2018 [cited 2021 Feb 13];12: 10-18. Available from: https://he01.tci-thaijo.org/index. php/JHR/article/view/164232 (In Thai).

28. Health administration division. Basic information of hospitals under the Office of the Permanent Secretary, Ministry of Public Health [monograph on the Internet]. Nonthaburi: Ministry of Public Health; 2019 [cited 2021 Jan 3]. Available from: https:// phdb.moph.go.th/main/index/downloadlist/57/0

29. Tabachnick BG, Fidell LS. Using multivariate statistics. $6^{\text {th }}$ ed. London: Pearson; 2013.

30. Martínez-Mesa J, González-Chica DA, Bastos JL, Bonamigo RR, Duquia RP. Sample size: how many participants do I need in my research? An Bras Dermatol 2014;89:609-15.

31. Sperber AD. Translation and validation of study instruments for cross-cultural research. Gastroenterology 2004;126(Suppl 1): S124-8.

32. Owlia M, Dodson JA, King JB, Derington CG, Herrick JS, Sedlis
SP. Angina severity, mortality, and healthcare utilization among Veterans with stable angina. J Am Heart Assoc 2019;8. doi: 10.1161/JAHA.119.012811.

33. Höfer S, Lim L, Guyatt G, Oldridge N. The MacNew Heart Disease health-related quality of life instrument: a summary. Health Qual Life Outcomes 2004;2:3.

34. Walker SN, Sechrist KR, Pender NJ. Health promotion modelinstruments to measure health promoting lifestyle: HealthPromoting Lifestyle Profile [HPLP II] (adult version) [monograph on the Internet]. Michigan: University of Michigan; 1995 [cited 2020 Jan 24]. Available from: https://deepblue.lib.umich.edu/ handle/2027.42/85349

35. Suwonnaroop N. Health-promoting behaviors in older adults: the effects of social support, perceived health status, and personal factors [Unpublished dissertation]. United States: Case Western Reserve University; 1999.

36. Sullivan MD, LaCroix AZ, Russo J, Katon WJ. Self-efficacy and self-reported functional status in coronary heart disease: A six-month prospective study. Psychosom Med 1998;60: 473-8.

37. Saengsiri A, Thanasilp S, Preechawong S. A psychometric evaluation of the Thai version of the cardiac self-efficacy questionnaire for patients with coronary artery disease. J Health Res [serial on the Internet]. 2013 [cited 2021 May 28];27:383-9. Available from: https://he01.tci-thaijo.org/index.php/ jhealthres/article/view/88724

38. Felton BJ, Revenson TA, Hinrichsen GA. Stress and coping in the explanation of psychological adjustment among chronically ill adults. Soc Sci Med 1984;18:889-98.

39. Janowski K, Kurpas D, Kusz J, Mroczek B, Jedynak T. Emotional control, styles of coping with stress and acceptance of illness among patients suffering from chronic somatic diseases. Stress Health 2014;30:34-42. 